\title{
Influence of duration of single dynamical events on the result of evaluation of human perception of vibration in buildings
}

\author{
Alicja Kowalska-Koczwara ${ }^{1, *}$, Filip Pachla ${ }^{1}$ and Veronika Valašková $^{2}$ \\ ${ }^{1}$ Cracow University of Technology, Institute of Structural Mechanics, 31-155 Kraków, Warszawska \\ 24 St., Poland \\ ${ }^{2}$ University of Žilina, Faculty of Civil Engineering, Department of Structural Mechanics and Applied \\ Mathematics, Univerzitná 8215/1, 01026 Žilina, Slovak Republic
}

\begin{abstract}
The duration of vibration taken to the analysis influence on the result of evaluation of human perception of vibration. In this paper the relationship between the duration of individual events and the result of RMS and VDV analysis was investigated. The analysis was carried out on two buildings located close to Warsaw Metro line 1. The chosen buildings are typical masonry buildings located in the city center and subjected to three sources of traffic vibrations: subway, tramway and road. Evaluation of human perception of vibration was made using two different methods, the most popular, root mean squared method (RMS) and vibration dose value method (VDV). Methodology of these two methods is also described in the paper. The results from RMS and VDV methods are compared by using HPVR (human perception of vibration ratio) for RMS analysis. It is ratio discovered by prof. Stypula and it is very useful for the diagnosis. The conclusion from analysis are given.
\end{abstract}

\section{Introduction}

Human perception of vibration is one of the most individual factor. It depends on age, sex and even nationality. The researchers mostly are focused on whole body vibrations that can be dangerous for bus drivers [1-3], construction workers [4-6] when they work with vibratory hammers, etc. Some of authors made an overall review [7-8] which can be very useful when you search national and international standards, requirements on the subject. Much less publications are on human perception of vibrations in buildings, when vibrations are felt passively. That is why the all requirements from whole body vibrations can be used for human passive perception of vibration [9-10]. In this paper only one of the aspect of human perception of vibration in buildings will be investigated, the duration of vibration. When the whole body vibration the duration of vibration is considered, we are talking about 8 or 12 hour exposure. But when we talk about people which are staying in their houses, and which are subjected to many traffic vibration which comes from different vibration sources, it is difficult to designate such exposure. In this paper the duration of single

*Corresponding author: akowalska@pk.edu.pl 
dynamical event on human perception of vibration is investigated. The two most popular methods of evaluation where used for this purpose: root mean squared method (RMS) and vibration dose value method (VDV) [9]. RMS method averages acceleration values in duration time and is defined as

$$
a_{w}=\left[\frac{1}{T} \int_{0}^{T} a_{w}^{2}(t) d t\right]^{\frac{1}{2}}
$$

where: $a_{w}(t)$ - is weighted acceleration as a function of time $\left[\mathrm{m} / \mathrm{s}^{2}\right] . T-$ is the duration of measurement [s].

VDV method uses fourth power instead of the second power as is used in RMS and it is defined as follows

$$
V D V=\left[\int_{0}^{T} a_{w}^{4}(t) d t\right]^{\frac{1}{4}}
$$

To compare these two methods with each other HPVR ratio [11] was used

$$
H P V R=\max \left(\frac{a_{R M S}}{a_{z}}\right)
$$

where: $a_{R M S}-\quad$ acceleration $R M S$ value obtained from analysis.

$a_{z}$ - acceleration $R M S$ value equivalent to the threshold for the perception of vibration in a $z$-direction in the same $1 / 3$ octave band as in $a_{R M S}$.

\section{Methodology}

Measurements were carried out on two chosen buildings which are located very close to Warsaw Metro Line 1. The buildings are typical masonry buildings. The first of the buildings on which a series of measurements were made is located in Warsaw at Zamoyski St. It is located at a distance of $9 \mathrm{~m}$ from the edge of a road and about $20 \mathrm{~m}$ from a tram line (distance measured from the nearest rail head) and located directly above the metro tunnel. The second building in which assessments were made was the building located at Targowa $76 \mathrm{St}$. It is a six-story building. The building is located $25 \mathrm{~m}$ from the metro tunnel, $9 \mathrm{~m}$ from the road and $25 \mathrm{~m}$ from the tram line. All three sources of vibration are located in so called zones of dynamic influences [12].

Measurements points were located in the middle of the floor acc. [13]. In building at Zamoyski St. it was located on the fourth floor and in the building at Targowa 76 St. was located at the third floor Fig. 1. The rooms chosen for measurements were located on the side of the building closer to traffic excitation. 
a)

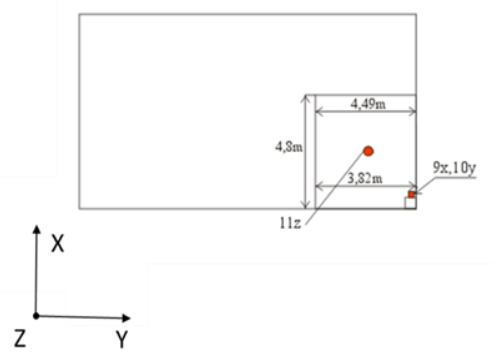

b)

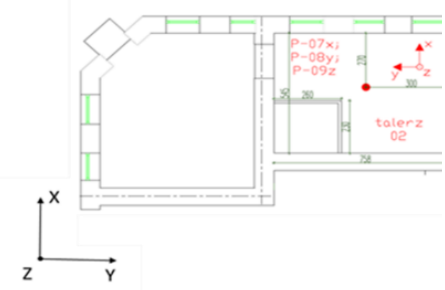

Fig. 1. Location of measurement points for human perception of vibration in both buildings:

a) Zamoyski St.; b) Targowa 76.

Acceleration was recorded in three directions: two horizontal (x,y) and one vertical $(\mathrm{z})$. An example of recorded signal is shown in Fig. 2.

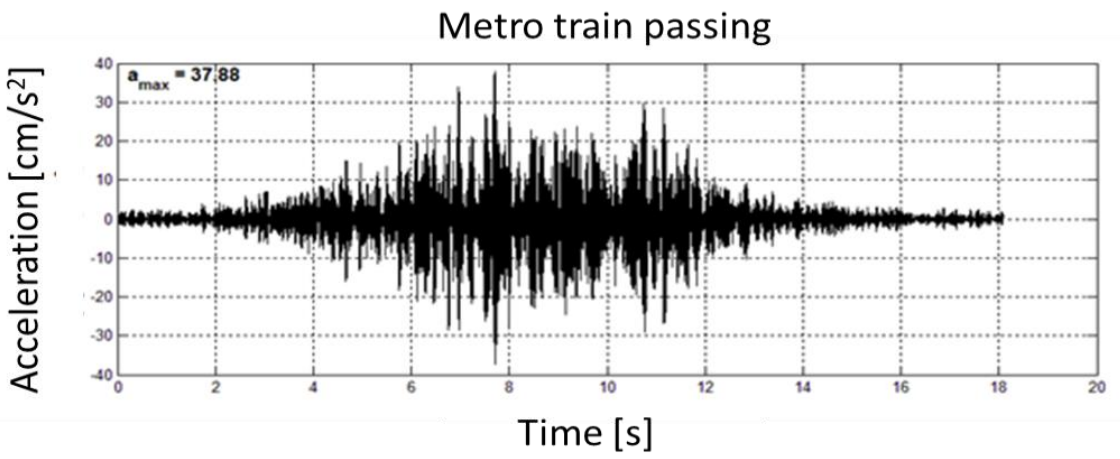

Fig. 2. Waveform recorded from metro train excitation, on the fourth floor in ' $z$ ' direction, in building at Zamoyskiego St.

\section{Analysis results}

Fig. 3-4 summarizes the results of the study on the influence of the type of transport source and the duration of a single event on the human perception of vibration expressed using the HPVR. The figures indicate lines corresponding to: the perception threshold of vibration in the " $z$ " direction (orange line) and the comfort line during the day (yellow line). In Fig. 3-4 and Fig. 5-6 there are abbreviations which correspond to transport vibration sources: $t$ tramway, $\mathrm{m}$-metro trains, $\mathrm{s}$ - road, heavy trucks.

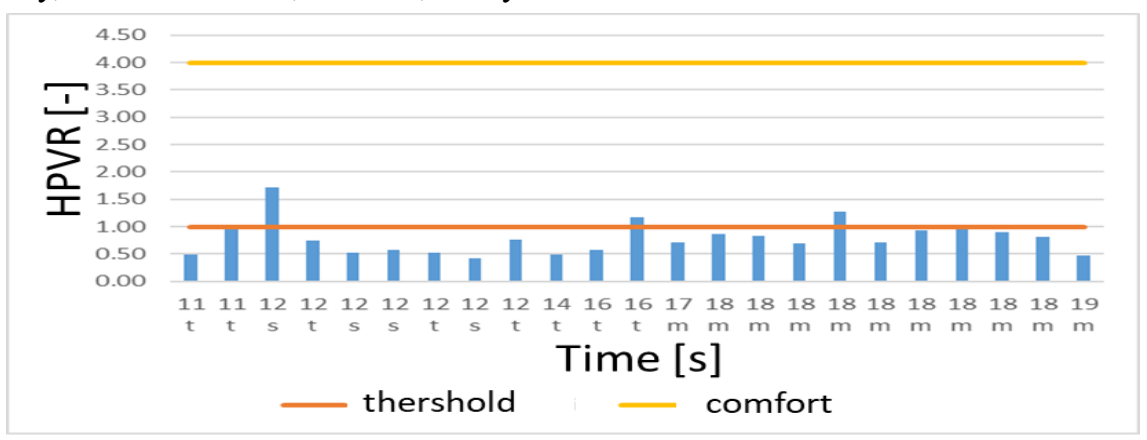

Fig. 3. Influence of transport source on the duration of vibration and on the HPVR value in building at Zamoyskiego St. 


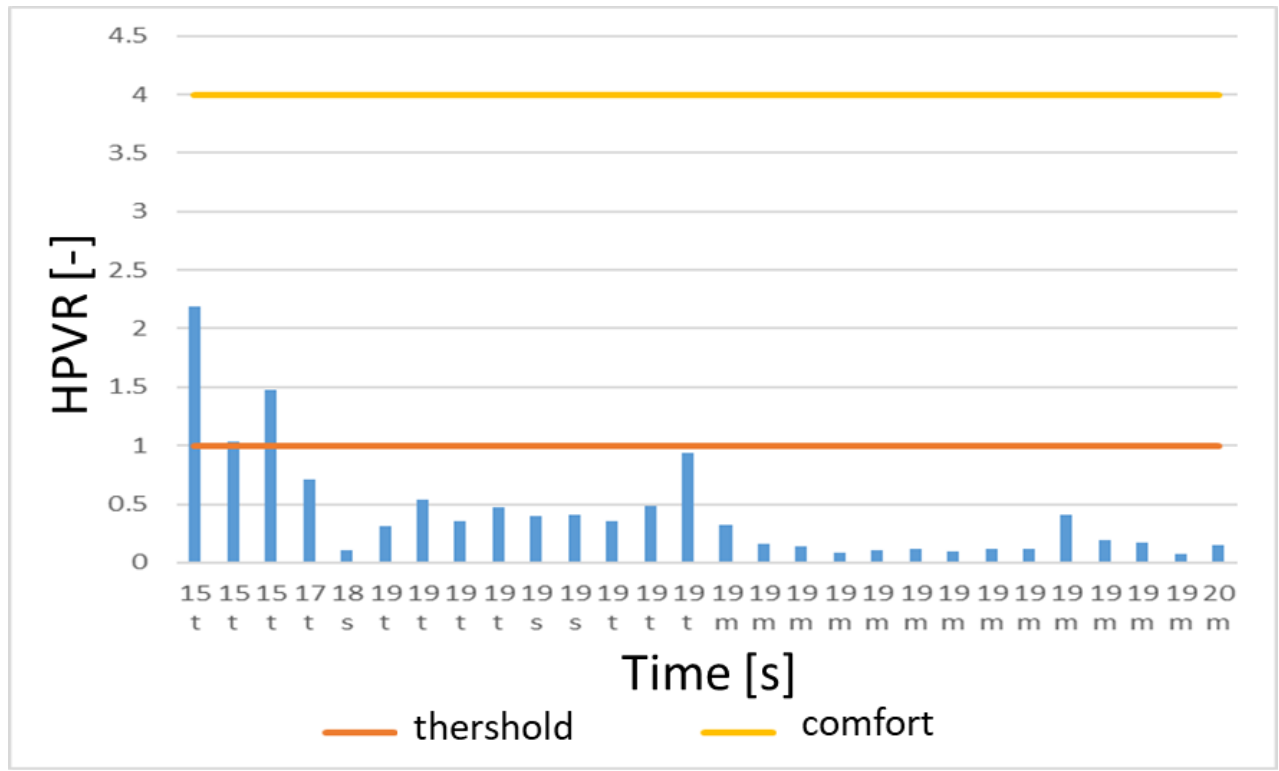

Fig. 4. Influence of transport source on the duration of vibration and on the HPVR value in building at Targowa $76 \mathrm{St}$.

From the results presented in Fig. 3-4, the influence of transport source on the duration of individual events is not possible to describe using the selected function.

An analogous analysis regarding the influence of the type of transport and the duration of vibrations on the result of human perception of vibration expressed by the VDV vibration dose value is presented in Fig. 5-6. Similarly to the previously described figures, in Figs. 5-6 there are lines corresponding to the perception threshold of vibration in the " $z$ " direction and comfort line during the day.

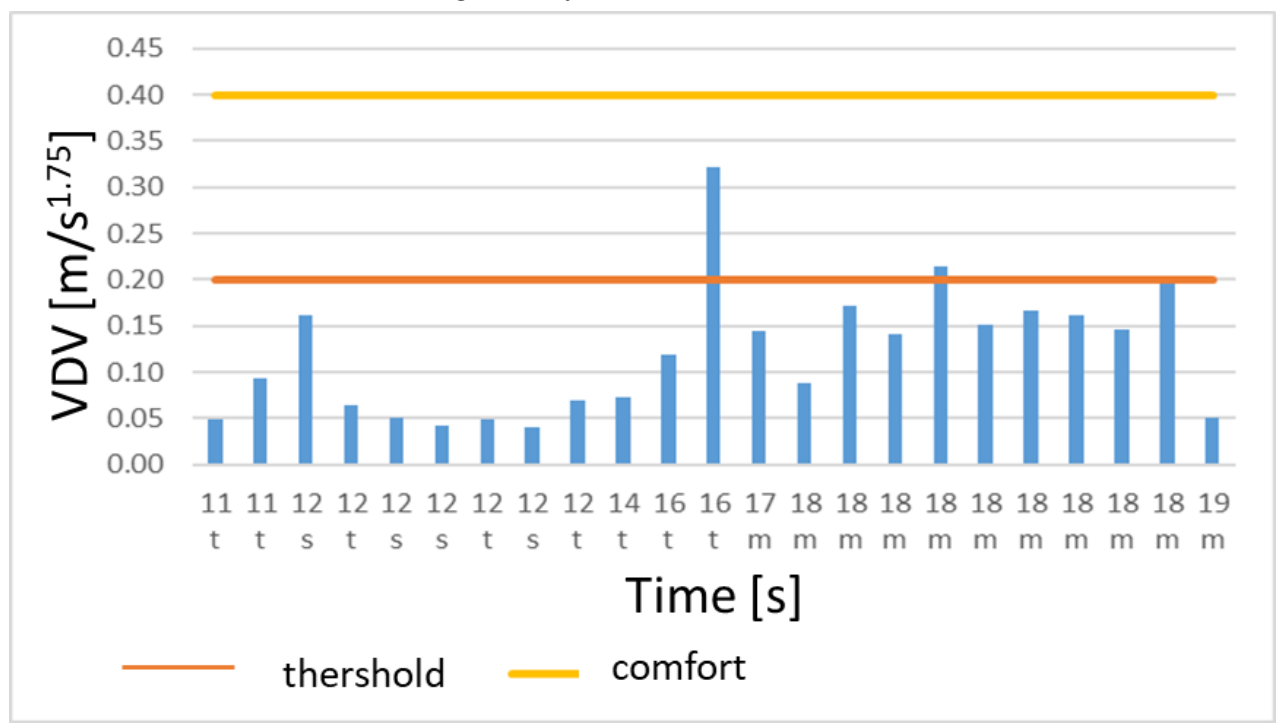

Fig. 5. Influence of transport source on the duration of vibration and on the VDV value in building at Zamoyskiego St. 


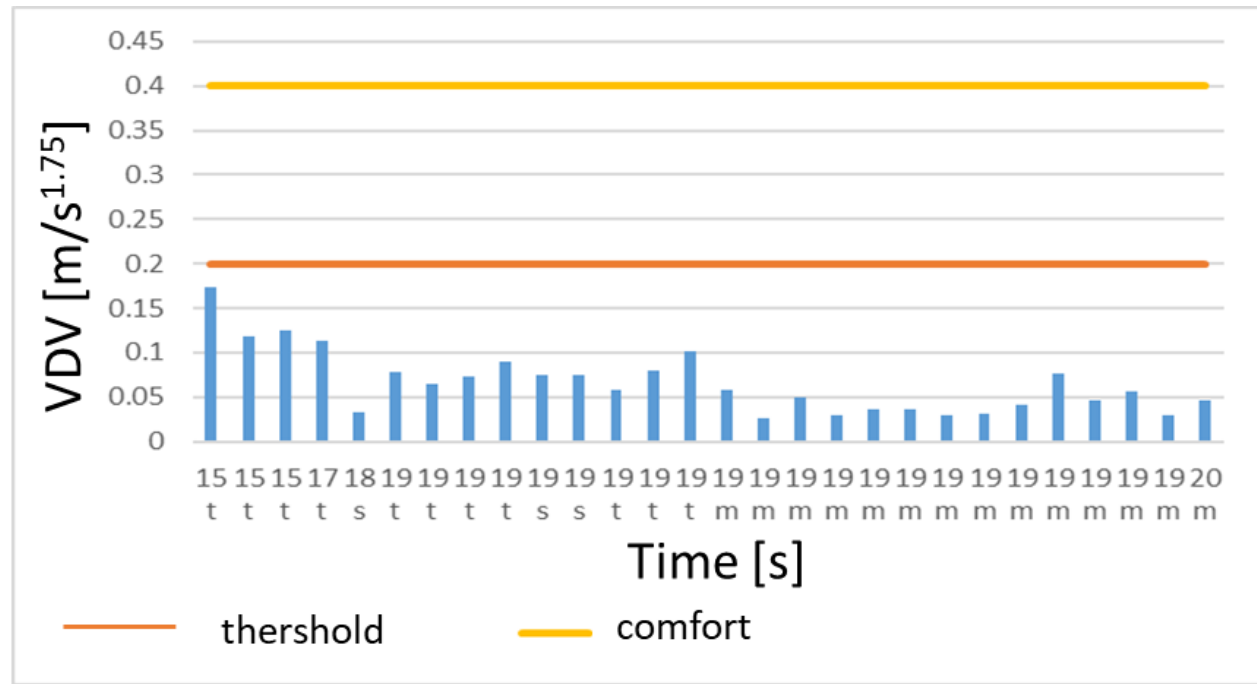

Fig. 6. Influence of transport source on the duration of vibration and on the VDV value in building at Targowa 76 St.

Based on the information summarized in Fig. 3-6, it is noticed that in relation to rail vehicles, the duration of vibration determined for trams is shorter than that determined in relation to the duration of vibration caused by metro trains. With regard to tram journeys, it is most often equal $11-15 \mathrm{~s}$, and with respect to journeys by metro trains $18-19 \mathrm{~s}$. Analyzes regarding car journeys referred to too few events, and the duration of vibrations corresponding to these events covered various conditions of travel. It is noted that with stabilized speed of travel and length of vehicles (tram, metro trains) the duration of vibrations in different measurements does not change much.

In Fig. 7 a classic statistic parameters are shown by using box and whisker plot. It is correlation between the source of vibration and a HPVR value for both buildings.

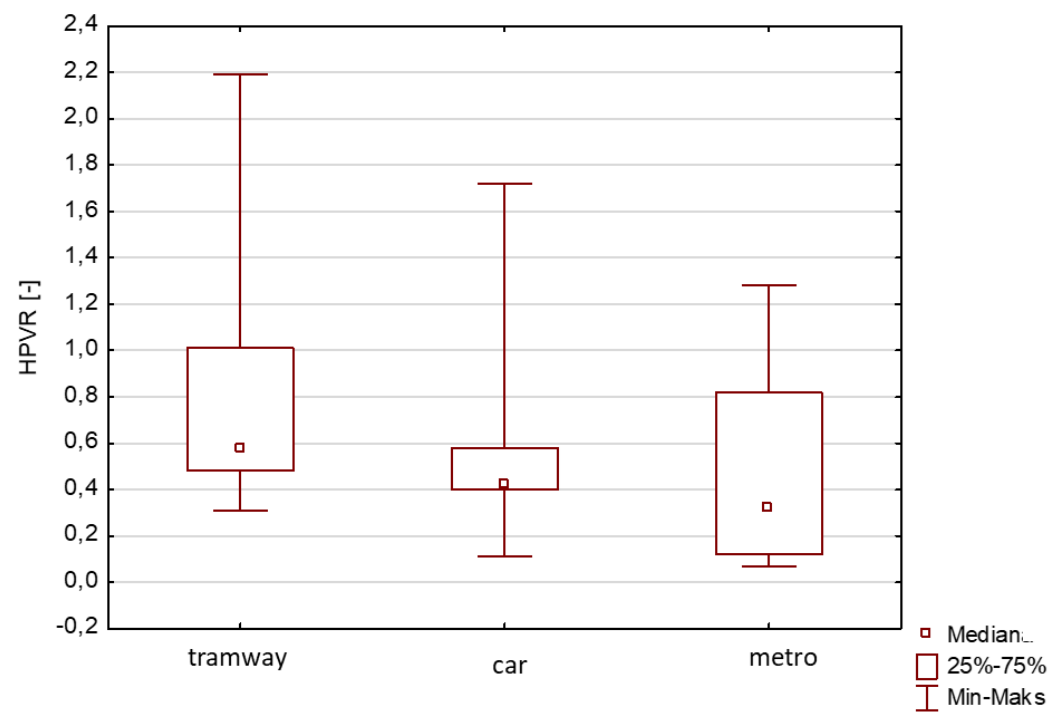

Fig. 7. Influence between the source of vibration and HPVR ratio. 
As could be seen from Fig. 7 the tramway and road have largest spread of results. The Metro results are most suited.

In Fig. 8 a box and whisker plot for relation between the source of vibration and duration for both buildings is shown.

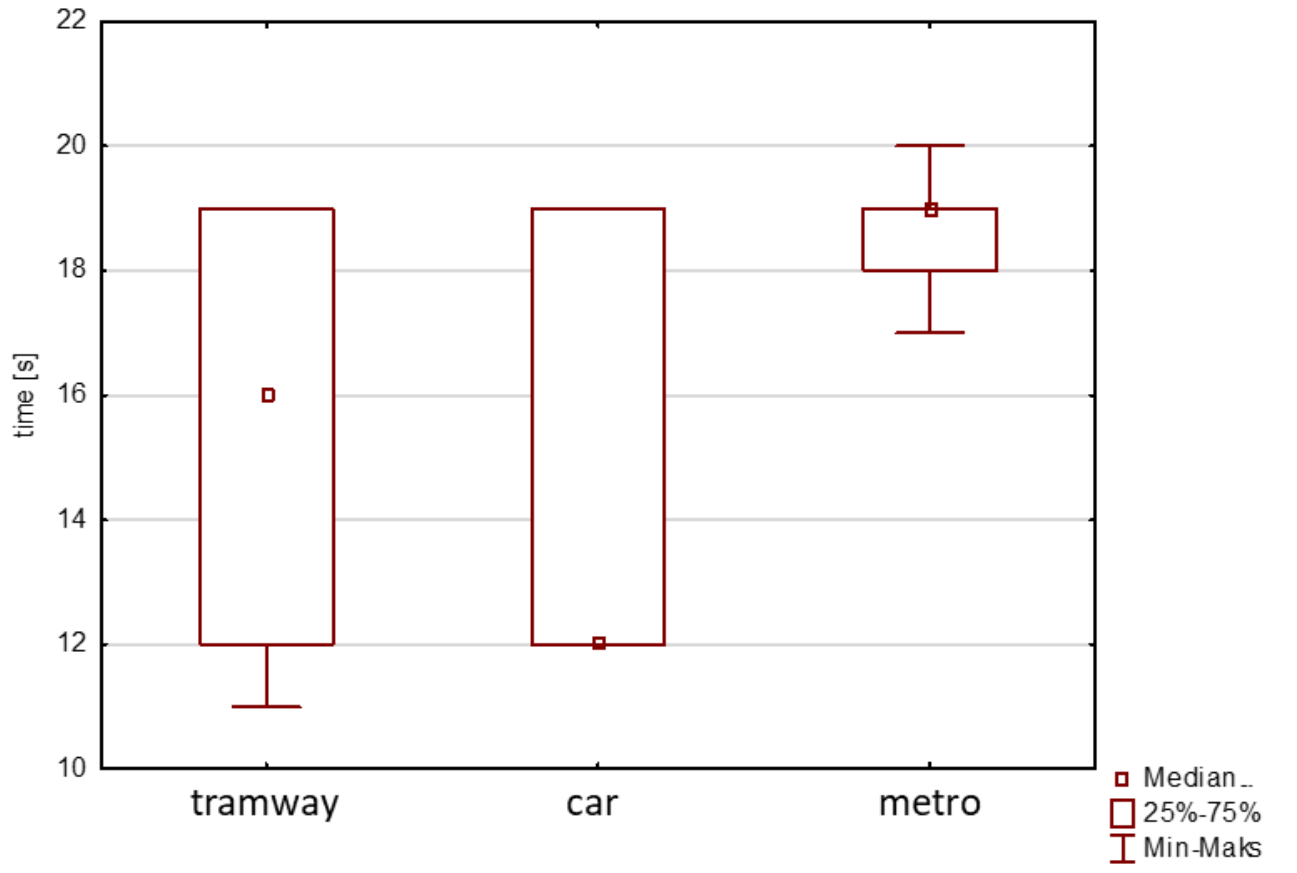

Fig. 8. Influence between the source and duration of vibration.

From Fig. 8 it could be noticed that results do not spread so much. It means there is correlation between the source of vibration and the time of vibration.

\section{Conclusion}

The article presents an investigation of influence of the source of vibration on human perception of vibration and on vibration time. There is no correlation between the vibration source and the HPV value. The HPVR values changed from 0.07 to 2.19 . Wherein the exceedance of perception threshold of vibration occur in all types of vibration source. The minimum value equal 0.07 was observed for metro train and the maximum for tramway.

The same situation is between the vibration source and the VDV value. The minimum value is equal 0.03 for car journey and the maximum is 0.32 for tramway.

There is however correlation between the source of vibration and the time of vibration when we the single dynamic event is considered. The average value, standard deviation, median for the three considered sources of vibration is given in Table 1. 
Table 1. Statistic parameters of relation between the source of vibration and time of vibration.

\begin{tabular}{|c|c|c|c|}
\hline Parameter & $\begin{array}{c}\text { Tramway time } \\
{[\mathbf{s}]}\end{array}$ & $\begin{array}{c}\text { Heavy car time } \\
{[\mathbf{s}]}\end{array}$ & $\begin{array}{c}\text { Metro train time } \\
{[\mathbf{s}]}\end{array}$ \\
\hline Average value & 15.7 & 14.8 & 18.6 \\
\hline $\begin{array}{c}\text { Standard } \\
\text { deviation }\end{array}$ & 3.0 & 3.6 & 0.6 \\
\hline Median & 16 & 12 & 19 \\
\hline
\end{tabular}

The results for heavy car time are the most spread while for metro trains are more compact. The number of observation for heavy car time is quite low for these buildings and is equal 7 events while for metro trains there have been 25 dynamical events recorded.

\section{References}

1. M. Bovenzi, A. Zadini, Spine, 17(9), 1048-1059 (1992)

2. R.P. Blood, J.D. Ploger, M.G. Yost, R.P. Ching, P.W. Johnson, J. Sound Vib. 329 (2010)

3. A. Burdorf, A., P. Swuste, P. Ann. Occup. Hyg., 37, 45-55 (1993)

4. N.K. Kittusamy, B. Buchholz, J. Saf. Res., 35, 255-261 (2004)

5. D. E. Wasserman, D. G Wilder, M. H Pope, M. Magnusson, A. R. Aleksiev, J. F. Wasserman, J. Occup. Environ. Med., 39, 403-407 (1997)

6. V.H.P. Vitharana, G.H.M.J. Subashi De Silva and G.S.y. De Silva, Soc. Struc. Eng. (2014)

7. B. O. Wikström, A. Kjellberg, U. Landström, Int. J. Ind. Ergon.14, 273-292 (1994)

8. M. J. Griffin. Handbook of human vibration. (Academic Press, Harcourt Brace Jovanovich)

9. ISO 2631-1, Guide to the evaluation of human exposure to whole body vibration. Part 1 - General requirements (2003)

10. AS 2670.2: Evaluation of human exposure to whole-body vibration - Continuous and shock-induced vibration in buildings ( $1 \mathrm{~Hz}$ to $80 \mathrm{~Hz}$ ), (1990)

11. J. Kawecki, K. Stypuła, Ensuring vibrational comfort for people in buildings exposed for transport impact (Publishing House of Cracow University of Technology, 2013)

12. A. Kowalska-Koczwara, K. Stypuła, MATEC Web of Conferences 107 (2017) 